\title{
The Influence of Climatic Factors on Spreading of Covid-19 Pandemic in Egypt During First Wave 2020
}

\author{
Abdelraouf A. Moustafa*, and Samira R. Mansour \\ Botany and Microbiology department, Faculty of science, Suez Canal University, Ismailia, Egypt
}

\begin{abstract}
The new SARS-CoV-2 coronavirus, the origin the COVID-19 pandemic, was stated in Wuhan, China, in December 2019. It causes severe acute respiratory syndrome that leads to death. Coronavirus-2 (SARS-CoV2) has, to date, infected more than 79 million people globally foremost to more than 1.7 million deaths and an extraordinary impact on facilities. Generally, this disease has rapidly disseminated all over the world in healthcare more than 200 countries including Egypt. To understand the impact of temperature and humidity on outbreak of this disease in Egyptian environment, this study was carried out to describe current knowledge about the appearance and speed of COVID-19 transmission. The daily recorded temperature (low and high T), and relative humidity (RH) in relation to the daily counts of COVID-19 cases in Egypt were evaluated. This study was undertaken since the data of daily infected people collected and announced daily by the Egyptian Ministry of Health and population (beginning of March till the first week of August, 2020). The results of our collected data, analyzed by using Pearson test, showed that the values of minimum temperature has significant influence on the increase of infected cases of COVID-19 $(\mathrm{r}=0.60, \mathrm{n}=160 ; p \leq 0.040)$. In the meantime, the multiple regression analysis revealed that the whole factors including minimum, maximum and relative humidity showed a positive significant relationship with the number of daily infected cases of COVID-19, (F. ratio= 125.375, $p \leq 0.000$ ). In parallel, the number of infection cases rapidly decreased with increasing in the recorded temperature, relative humidity and UV index.
\end{abstract}

Keywords: Corona virus, CVIDO19, climate, temperature, relative humidity.

\section{INTRODUCTION}

Coronaviruses are a group of RNA related viruses that can cause disease in both animals and humans, some strains of coronaviruses are zoonotic, sense they can be transmitted between animals and humans. They illness ranging from the common cold to more severe diseases such as Middle East Respiratory Syndrome have characteristic club-shaped protein spikes that project from their surface. These spike proteins are surrounding the virus lipid envelope like a crown (corona). An image, taken by electron micrographs, showed reminiscent of the solar corona from which their name was driven. In humans, coronaviruses can cause (caused by MERS-CoV), and Severe Acute Respiratory Syndrome (caused by SARS-CoV). More detailed studies have demonstrated that MERS-CoV was transmitted from dromedary camels to humans and SARS-CoV from civets to humans. MERS-CoV was first reported in Saudi Arabia in 2012 and has since spread to several other countries. Most people infected with MERS-CoV developed severe respiratory illnesses who suffer from fever, cough, and shortness of breath that can be ended with death. Meanwhile, a new strain of coronavirus, named "Severe Acute Respiratory Syndrome Coronavirus 2" (SARS-CoV-2), was identified as the causative agent of human illness. This virus causes coronavirus disease 19 that known by COVID-19. Most people diseased with the COVID-19 virus will run-through slight to sever respiratory infection and can recover without demanding special treatment. However, elder people, people with weakened immune systems and those who suffer from primary medical difficulties like cardiovascular disease, diabetes, chronic respiratory disease, and cancer are more likely to develop serious illness. Sporadic human cases of SARS-CoV-2 have occurred and continue to occur over a wide geographical distribution with the majority of the cases reported from the China, Europe and United states. Since then, human cases have been also reported by almost all countries around the world and the COVID-19 outbreak has been declared a pandemic by the World Health Organization (WHO, 2020).

The current pandemic, SARS-CoV-2, is being considered as contiguous disease since it proved to sustain through human to human. The virus can be transmitted when any individual is in close contact with someone infected where the droplets of saliva, that come out from mouth or breathe and discharge from the nose, saturated in air and moved to another individual. However, other way of virus transmission is through contaminated surfaces where larger droplets carrying the virus, can fall down into different surfaces and be a source of infection. Meanwhile, the origin source or the route of transmission to humans, which may have involved an intermediate host, is not known. Current evidence suggests that SARS-CoV-2 may emerge from an animal source. Although, genetic sequence data reveals that the closest known relative of SARS-CoV-2 is a coronavirus circulating in the populations of Rhinolophus bat (Horseshoe Bat), but up till now no enough scientific evidence to identify the origin rout of transmission. In consideration of COVID-19 is RNA-virus, with about 120 nanometers in diameter, it is susceptible to mutations, consequently different varieties can develop and they mostly may infect human (Aronson, 2020).

Previous studies have supported an epidemiological hypothesis that climatic conditions may affect the

*Corresponding author e-mail: raoufmoustafa2@hotmail.com 
active existence, survival and spread of dropletmediated viral diseases. Considering the existing scientific evidence, cold and dry climates may facilitate the survival and spread of COVID-19. In parallel, warm and wet climates seem to reduce the viral load and in sequence reducing the spread of COVID-19 transmission. However, these variables alone could not explain most of the variability in disease transmission. Therefore, all countries all over the world, especially the most affected ones and recorded high mortality rate, should focus on health policies, even with climates less favorable to the virus. In the light of spreading this disease no clear assessment of climate influence was recorded in Egypt. Therefore, our study was focused on disaggregated recorded data at multiple levels to capture the links between the COVID-19 outbreak and weather conditions (temperature and relative humidity).

\section{Current situation of Covid-19 in Egypt}

Egypt is a huge country and the desert land characterizes the largest portion of it area. Furthermost Egyptian (95\% of Egypt's total people) lives in areas around the coasts of the Mediterranean Sea and along the Nile River. This includes the cities of Cairo, Alexandria, Aswan, and Port Said. The current population of Egypt, up till Tuesday, August 4, 2020, is $102,500,680$, based on World meter explanation of the latest United Nations data. Egypt population is equal to $1.31 \%$ of the total world population and ranks number 14 in the list of countries (and dependencies) by population. The population density in Egypt is 103 per $\mathrm{Km}^{2}$ and the total land area is 995,450 $\mathrm{Km}^{2}$, nevertheless $43.0 \%$ of the population is urban (44,041,052 people, as recorded in 2020). Egypt is considered as one of the extraordinary countries due to the richness of its history and the meaning of its position between the other countries. Egypt is located in the north east part of Africa and covers around $1,001,450 \mathrm{~km}^{2}$. Due to Egypt's extraordinary position, Egypt is well known as one of the most powerful countries in the Middle East and the Muslim world.

Egypt's large population makes the country extremely vulnerable to COVID-19 pandemic. Even though, Egypt's climate is semi-desert characterized by hot dry summers, moderate winters and particularly good wind regimes nonetheless SARS-CoV-2 is spreading all over the country especially in the governorates located in lower of Egypt. The rate of infected people, recorded by Egypt's Minister of Health, was increased in winter, 2020.

\section{Climate of Egypt}

While different regions experience diverse weather patterns, Egypt has an arid desert climate and is very hot and sunny climate. In fact, Egypt fundamentally has a hot desert climate (Köppen climate classification). The climate is generally tremendously dry all over the country except on the northern Mediterranean coast which receives rainfall in winter. In addition to rarity of rain, extreme heat during summer months is also a general climate feature of Egypt although daytime temperatures are more moderated along the northern coast (Weather Atlas/Egypt, 2020).

Generally, as part of the northern hemisphere, seasons in Egypt follows the similar pattern as in America and Europe with winter falling between November and January, and the highest peak summer months is falling between June and August. Winters are normally mild, and temperatures can fall below $10^{\circ} \mathrm{C}$ degrees at night. Frequently in desert, temperature dropped below freezing during the winter months. Summer is extremely hot in the desert areas and other areas of the country's interior. In Cairo, average summer temperatures regularly exceed $30^{\circ} \mathrm{C}$ degrees, while as the highest degree of temperature recorded in Aswan, $51^{\circ} \mathrm{C}$ degrees (Figure 1). Egypt receives usually between 20 to $200 \mathrm{~mm}$ of annual average precipitation along the narrow Mediterranean coast, and zero mm towards to the south. The cloudiest, rainiest places are in and around Alexandria and Rafah. An overview for the climate of Egypt recorded in this year (Table 1) showed different parameters in which a correlation between UV index and the day temperature. In parallel, there is a positive correlation between time for sunshine and UV index. To explore the link between climatic variation and COVID-19 transmission, we used the daily high and low temperature, humidity, and UV index with the infected number of cases with COVID-19, separately. In meantime, different statistical analysis was applied including the Pearson correlation test and multiple regression analysis.

Table (1): An overview of different climatic parameters of Egypt during March to August 2020.

\begin{tabular}{lcccccc}
\hline \hline \multirow{2}{*}{ Measured climatic parameters } & \multicolumn{7}{c}{ Months } \\
\cline { 2 - 7 } & March & April & May & June & July & August \\
\hline Day temperature & 23.5 & 28.3 & 32.0 & 33.9 & 34.7 & 34.3 \\
Night temperature & 11.6 & 14.6 & 17.7 & 21.1 & 22.0 & 22.0 \\
Absolut Humidity $\mathbf{g} / \mathbf{m}^{\mathbf{3}}$ (approx.) & 8.0 & 9.6 & 11.0 & 13.7 & 16.0 & 16.6 \\
UV index (A) & 7.0 & 9.0 & 10.0 & 12.0 & 12.0 & 11.0 \\
Sunshine/h & 8.0 & 9.7 & 10.5 & 11.9 & 11.7 & 11.3 \\
Day light/h & 12.0 & 12.9 & 13.7 & 14.1 & 13.9 & 13.2 \\
Rainy days per month & 1.0 & 0.6 & 0.4 & 0.0 & 0.0 & 0.0 \\
\hline \hline
\end{tabular}




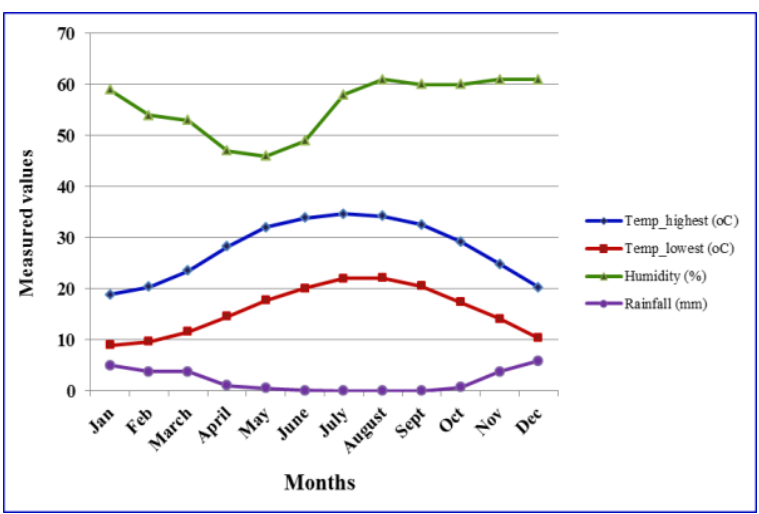

Figure (1): Climatic information for Egypt, comprising the average of the highest and lowest temperatures; relative humidity and amount of rainfall during the year 2020 .

\section{Data interpretation}

The association between climatic factors and number of infected cases of COVID-19 extended for 6 months, started from March till August, 2020 (Figure 2). The first infected case with COVID-19 was documented on March fifth, 2020 in Egypt, and then started the infected cases increased gradually in April, May, only cases subjected to medical investigation, and it reached to the highest peak number in June where the temperature was very high $\left(33.9{ }^{\circ} \mathrm{C}\right)$ and started to decrease by time at the end of July and beginning of August. The mean values of infected in March was the lowest value for whole period of our study (22.87, reported case only) and the highest mean value was in June, (1444.2). The number of infected cases decreased in August to reach around 100-200 person daily. The results of statistical analysis, one way ANOVA, showed variation in the infected cases and the climatic factors as follows: 1- Infected cases were varied significantly in five months as categories $(\mathrm{F}=166.9653$, $p \leq 0.000), 2-$ The variation of daily minimum temperature $(\mathrm{F}=114.4480, p \leq 0.000), 3$-The variation of daily maximum temperature $(\mathrm{F}=57.5238, p \leq 0.000)$, and 4 -The variation of relative humidity $(\mathrm{F}=10.0734$, $p \leq 0.000$ ).

The output of correlation test (Pearson test) showed that there a significant correlation between the increasing in the infected case with daily minimum temperature $(r=0.5973, n=160, p \leq 0.041)$, on the other hand the correlation between highest temperature recorded and the infected case was not significant $(r=0.5692$, $\mathrm{n}=160, p \leq 0.1156$ ). Meantime, there is no significant correlation, between infected cases and relative humidity ( $\mathrm{r}=-0.2788, \mathrm{n}=160, p \leq 1.000)$. This result is in reverse to actual relation recorded by other studies (Shi et al., 2020; Tosepu, 2020 and Liu et al., 2020) and may be explained by the existence of many infected cases not reported or not confirmed. However, a study done by Zonglin et al., (2020) stated that the number of daily new confirmed cases reported in different cities in China were inconsistent across cities and lagged time, suggesting not only meteorological factors were greatly influence the COVID-19 epidemic but other health issues and population density are involved.

The results of multiple regression analysis, considering the infected cases as independent factors and those of minimum, maximum temperature and relative humidity as a variables, showed a significant correlation, which it means that infection cases decreased with increasing in temperature and relative humidity $(\mathrm{F}$ ratio $=125.375, p \leq 0.000$; and $\mathrm{F}$ ratio $=0.0240, p \leq 0.000$ ) for minimum, maximum and relative humidity respectively. UV index also showed significant influence on reduction of newly infected-SARS-CoV-2 cases.

\section{DISCUSSION}

The number of infected cases to date indicates a very rapid and efficient human-to-human virus transmission which continues to evolve globally. Since the outbreak of the novel SARS-like coronavirus (SARS-CoV-2) or

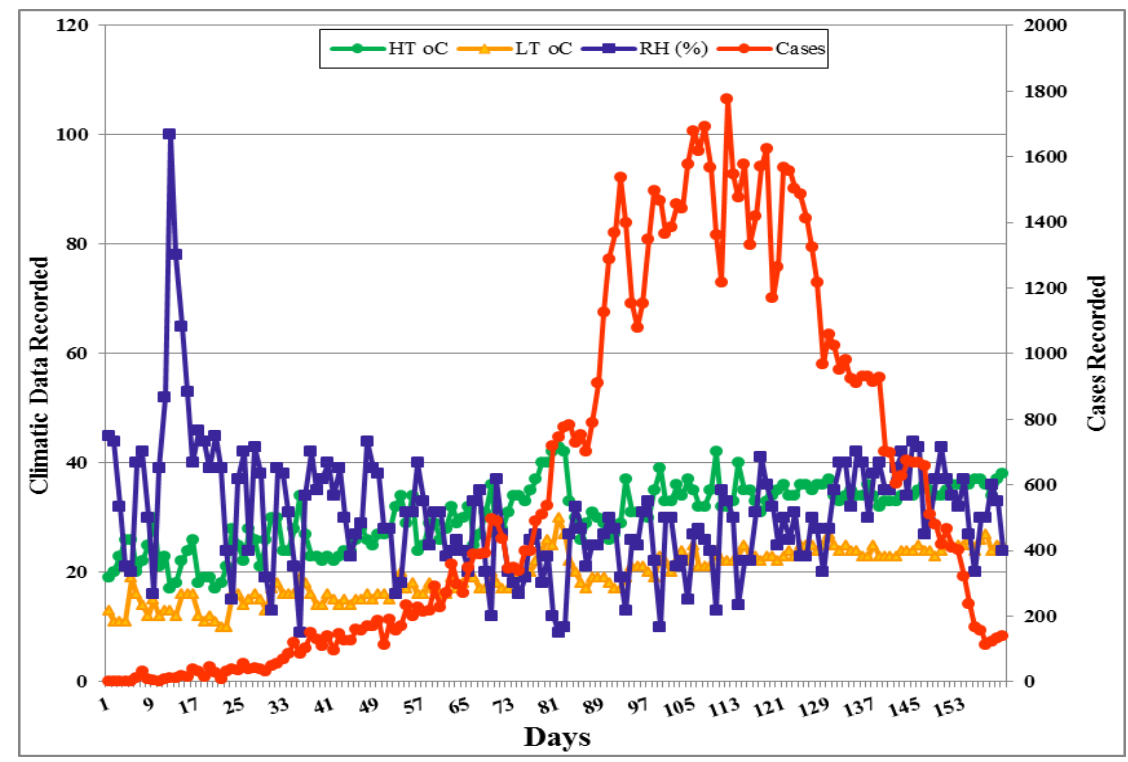

Figure( 2): The relationship between number of infected cases with COVID-19 and climatic factors including highest temperature (HT), lowest temperature, and relative humidity (RH) during March till first week of August 2020. 
what is known nowadays by COVID-19, a large number of reports have been published to discuss the possible roles of environmental factors in transmission of this novel coronavirus. Mostly, they have focused especially on the impact of two air parameters, temperature and humidity, on the spread of COVID-19. Yet, to date, no studies have been undertaken to understand the climatic role in the intensity of COVID19 transmission in Egypt. Our study aims to fully understand this gap by providing statistical evidence on the influence of climatic variables on the intensity of COVID-19 spread in Egypt. Therefore, our present study focused on finding the associations between the outbreak of COVID-19 in Egypt and the variation in temperature and relative humidity. Our study is in agreement with the recent studies carried out to explore these relations.

In context of this issue, Liu et al., (2020) projected to explore the associations between novel coronavirus disease 2019 (COVID-19) case counts and meteorological factors in 30 provincial capital cities of China. They found that meteorological factors play an independent role in the COVID-19 transmission after controlling population migration. In fact, their local weather conditions were with low temperature, mild diurnal temperature range and low humidity likely favour the transmission.

Another study in China by Shi et al., 2020, they studied the effects of temperature on the dynamics of the COVID-19 epidemic. They found that overall epidemic intensity of COVID-19 reduced slightly following days with higher temperatures with a relative risk (RR) was 0.96 (95\% CI: 0.93, 0.99), in general the increase in temperature affect the spread of the virus. The third main study in China was done by Qi et al., 2020, they sought to examine the associations of daily average temperature (AT) and relative humidity (ARH) with the daily counts of COVID-19 cases in 30 Chinese provinces (December 1, 2019 to February 2020). They found that main conclusion was AT and ARH showed significantly negative associations with COVID-19 with a significant interaction between them $(0.04,95 \%$ confidence interval: 0.004-0.07). They found that every $1{ }^{\circ} \mathrm{C}$ increase in the AT led to a decrease in the daily confirmed cases by $36 \%$ to $57 \%$ when ARH was in the range from $67 \%$ to $85.5 \%$. Also, they concluded that every $1 \%$ increase in ARH led to a decrease in the daily confirmed cases by $11 \%$ to $22 \%$ when AT was in the range from $5.04^{\circ} \mathrm{C}$ to $8.2^{\circ} \mathrm{C}$.

Similar study done by Xie and Zhu (2020), aimed to determine whether the temperature is an important factor in the transmission of infection caused by COVID-19. The daily infected cases and climatic factors in 122 cities were collected along January 23, 2020, to February 29, 2020. They found that mean temperature has a positive linear relationship with the number of COVID-19 cases with a threshold of $3{ }^{\circ} \mathrm{C}$ but there is no evidence supporting that case counts of COVID-19 could decline when the weather becomes warmer. This study disagrees with our results which proved significant correlation between the decreasing in infected cases and increasing in temperature and relative humidity.

In parallel, a study done by Yao et al., (2020) to determine the association of meteorological factors with the transmission of COVID-19 in various Chinese cities. They used the cumulative number of confirmed cases from 224 cities; they found no significant associations of, relative humidity, maximum temperature and minimum temperature with cumulative incidence rate or $\mathrm{R}_{0}$ of COVID-19.

In USA, a recent study done by Bashir et al., (2020), to point to the association between COVID-19 and climate indicators but in New York City, USA. They used secondary published data from New York City health services and National weather service, USA. They used the climate indicators including average temperature, minimum temperature, maximum temperature, and relative humidity quite similar to what we done but they added more climatic factors such as rainfall, wind speed, and air quality. Our results agreed with this study in which the increasing in temperature degrees affects the infection rate and its spreading. The findings of this study will help World Health Organization and health regulators such as Centre for Disease Control (CDC) to combat COVID19 in New York and the rest of the world.

In Jakarta, Indonesia, another study carried out by Tosepu et al., (2020), to explore the correlation between weather and COVID-19 spreading, they found that only temperature average $\left({ }^{\circ} \mathrm{C}\right)$ out of measured parameters of weather; include minimum and maximum temperature $\left({ }^{\circ} \mathrm{C}\right)$, temperature average $\left({ }^{\circ} \mathrm{C}\right)$, humidity $(\%)$, and amount of rainfall $(\mathrm{mm})$. They found that only temperature average $\left({ }^{\circ} \mathrm{C}\right)$; was significantly correlated with COVID-19 pandemic ( $\mathrm{r}=0.392 ; p$ $\leq .01$ ). Their finding is agreed with our present study for Egypt.

In Spain, a study done by Briz-Redón and SerranoAroca (2020), also this year on our topic but they concluded that there is no evidence suggesting a reduction in COVID-19 cases at warmer mean, minimum and maximum temperatures has been found. In the meantime they emphasized that these results need to be interpreted cautiously given the existing uncertainty about COVID-19 data. Subsequently, our study with more studies are describe and important to be there for the scientific community.

An interesting study done by Jahangiri et al., (2020), they intend to investigate the sensitivity of Temperature and population size on the transmission rate of COVID-19, the novel coronavirus in different provinces of Iran. On contrary with our results of present study, they had no scientific reason to confirm that the number of COVID-19 cases in warmer climates is less than that of moderate or cold climates. Therefore, they recommended their cities/provinces with a population of over 1.7 million people have stricter inspections and more precise controls as their management policy.

Eventually, our results showed an association between infected cases and the climatic factors 
including temperature and relative humidity. In fact, COVID-19 pandemic is presently exhibiting an even more adverse movement. Our results suggest that the growth rate of COVID-19 may increase with decrease in temperature and humidity. However, COVID-19 is in a stage of low infectivity and rapid transmission in Egypt and arid land generally. We think that our country and neighbours countries with same climate should take active and precise measures to control the rest stage of first pandemic and prevent a second wave of COVID-19.

Most importantly, increase of the UV index has also shown a decrease in the number of cases. This is evident from the fact that the global UV index map averaged over the time period of the study. This finding is strongly confirmed by data obtained by Gunthe et al., (2020)

Future studies, will have more variables including ecological, meteorological, and economical to models, are in need to understand the spreading behaviour of COVID-19. These varied multidisciplinary new researches will directly benefit individuals in low- and middle-income countries, provide learning opportunities globally to prevent virus outbreak. However, heath issues have to be spotted urgently to decrease the virus transmission.

\section{CONCLUSION}

Our present findings deliver initial evidence that the COVID-19 pandemic suppressed with temperature, UV index and relative humidity increases. However, active and precise measures must be taken to control the source of infection, block transmission and prevent any further spread of COVID-19 in the country.

\section{REFERENCES}

Aronson J. K (2020) Coronaviruses - a general introduction. https://www.cebm.net/covid19/coronaviruses-a-general-introduction/

Bashir MF, Ma B, Bilal, Komal B, Bashir MA, Tan D, et al. , (2020).Correlation between climate indicators and COVID-19 pandemic in New York, USA. Sci Total Environ. 728:138835. doi: 10.1016/j.scitotenv.2020.138835

BRIZ-REDÓN, Á. \& SERRANO-AROCA, Á. (2020). A spatio-temporal analysis for exploring the effect of temperature on COVID-19 early evolution in Spain. The Science of the total environment, 728, 138811.

GUNTHE SS, SWAIN B, PATRA SS, AMTE A. On the global trends and spread of the COVID-19 outbreak: preliminary assessment of the potential relation between location-specific temperature and
UV index [published online ahead of print, 2020 Apr 24]. Z Gesundh Wiss. 2020;1-10. doi:10.1007/s10389-020-01279-y

JAHANGIRI M, JAHANGIRI M, NAJAFGHOLIPOUR M. (2020).The sensitivity and specificity analyses of ambient temperature and population size on the transmission rate of the novel coronavirus (COVID-19) in different provinces of Iran. Sci Total Environ.728:138872. doi: 10.1016/j.scitotenv.2020.138872

LIU J, ZHOU J, YAO J, ZHANG X, LI L, XU X, et al., (2020) Impact of meteorological factors on the COVID-19 transmission: a multi-city study in China. Sci Total Environ. 726:138513. doi: 10.1016/j.scitotenv.2020.138513

QI H, XIAO S, SHI R, WARD MP, CHEN Y, TU W, et al.,(2020). COVID-19 transmission in Mainland China is associated with temperature and humidity: a time-series analysis. Sci Total Environ. 728:138778. doi: 10.1016/j.scitotenv.2020.138778

SHI P, DONG Y, YAN H, ZHAO C, LI X, LIU W, et al., (2020).Impact of temperature on the dynamics of the COVID-19 outbreak in China. Sci Total Environ. 728:138890. doi:10.1016/j.scitotenv.2020.138890

TANG, JULIAN (2009).The effect of environmental parameters on the survival of airborne infectious agents, Journal of the Royal Society, Interface / the Royal Society.

TOSEPU R, GUNAWAN J, EFFENDY DS, et al., (2020). Correlation between weather and Covid-19 pandemic in Jakarta, Indonesia. Sci Total Environ.;725:138436. doi:10.1016/j.scitotenv.2020.138436

Weather Atlas/Egypt (2020). https://www.weatheratlas.com/en/egypt-climate

WHO (2020). World Health Organization. https://www.who.int/health-topics/coronavirus\#tab=tab_1

Xie J \&Zhu Y. (2020). Association between ambient temperature and COVID-19 infection in 122 cities from China. Sci Total Environ. 724:138201. doi: 10.1016/j.scitotenv. 138201

YAO Y, PAN J, LIU Z, MENG X, WANG W, KAN $\mathrm{H}$, et al., (2020).No association of COVID-19 transmission with temperature or UV radiation in Chinese cities. Eur Respir J. 55:2000517. doi: 10.1183/13993003.00517.

ZONGLIN HE, YIQIAO CHIN, JIAN HUANG, YI HE, BABATUNDE O. AKINWUNMI, SHINNING YU, CASPER JP ZHANG, WAI-KIT MING (2020). Meteorological factors and domestic new cases of coronavirus disease (COVID-19) in nine Asian cities: A time-series analysis. medRxiv 2020.04.15.20066613; doi: https://doi.org/10.1101/2020.04.15.20066613 


\section{تأثير العوامل المناخية على انتثار جائحة كوفيا -19 في مصر خلال الموجة الأولى 2020}

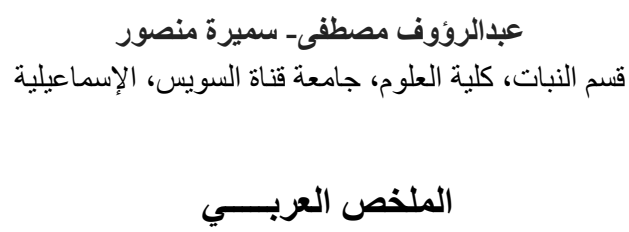

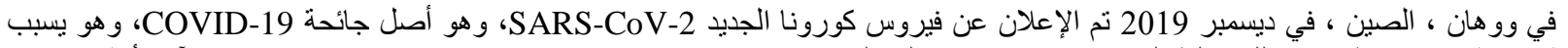

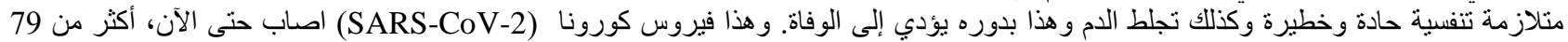

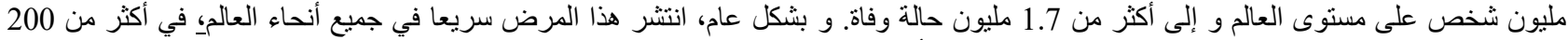

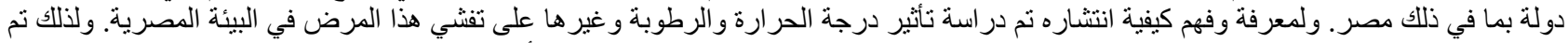

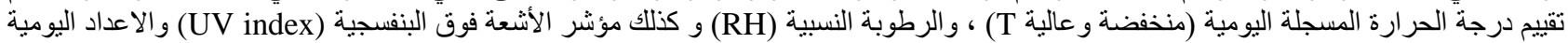

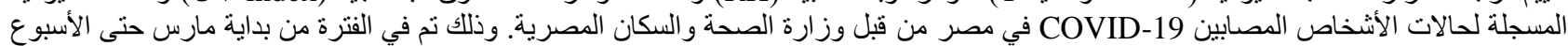

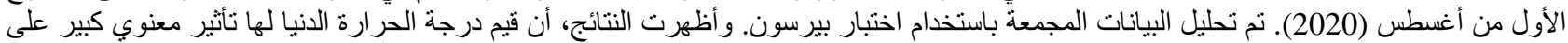

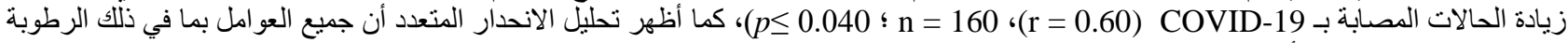

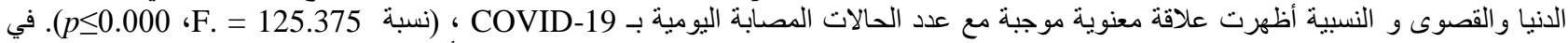
مو از اة ذلك، انخفض عدد حالات الإصابة بسر عة مع زيادة درجة الحر ارة المسجلة و الرطوبة النسبية ومؤشر الأشعة فوق البنفسة النفية. 